\title{
47. Result of the Precise Levelling along the Pacific Coast from Kôti to Kagosima, 1932.
}

\author{
By Torahiko TERADA, M.I.A.
}

(Comm. April 12, 1933.)

Precise levelling along the SE coast of Sikoku was already made in 1929 and the comparison of the result with that of the earlier levelling was reported by Prof. Imamura in Vol. 6 (1930), p. 101 of the Proceedings. The route revised in that occasion extended from Komatusima, Awa, to Susaki, Tosa, via Murotozaki and Kôti. An urgent need was since then felt to extend the revision of levelling further toward $\mathrm{W}$ along the coast of Tosa and, if possible, to the Pacific coast of Kyûsyû. To meet this need a substantial sum was granted, at the request of late Prof. Suyehiro and the present author, from the research fund of Harada-Sekizenkwai, in favour of the Earthquake Research Institute, by means of which the levelling was carried out during July-Nov. of 1932 along the route shown in the map of Fig. 1. The result of this survey was compared with that of

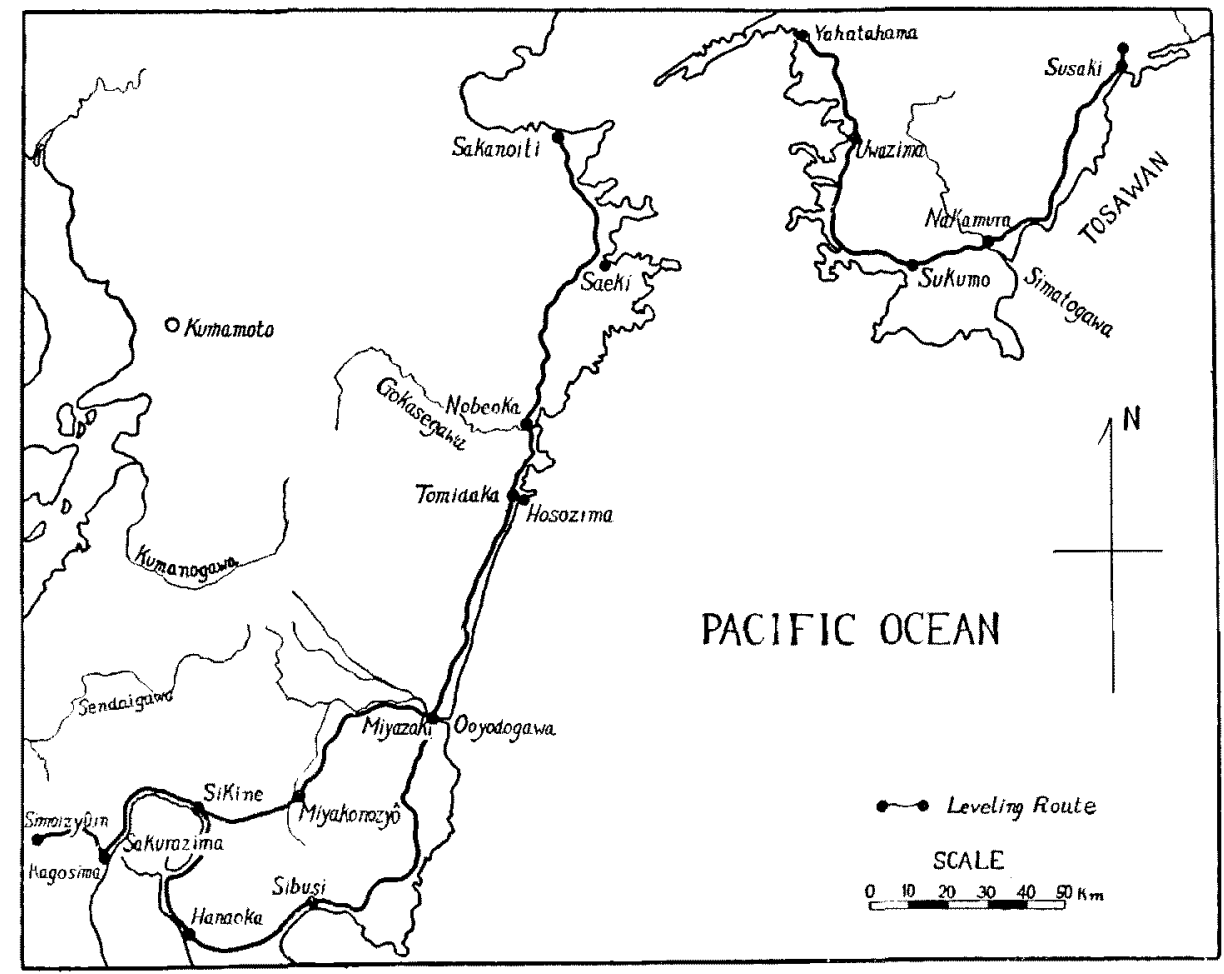

Fig. 1. 
the earlier levelling and the vertical displacements of the bench-marks were deduced, which are shown in Fig. 2, 3 and 4. The dates of the earlier levellings for the different sections of the route are given at the bottom of the respective figures. The vertical displacements in each Fig. are referred to an arbitrary zero, as respectively noted down below the figure. In the case of Fig. 2, Susaki, B.M. No. 4673, gives -12.2 $\mathrm{mm}$ relative to the assumed zero at B.M. No. 4677. According to Prof. Imamura, loc. cit., B.M. No. 4673 showed in 1929 an elevation of 141.2 relative to Tatue. B.M. No. 5079, near Komatusima. The latter B.M. could be assumed nearly stationary since 1896, as far as

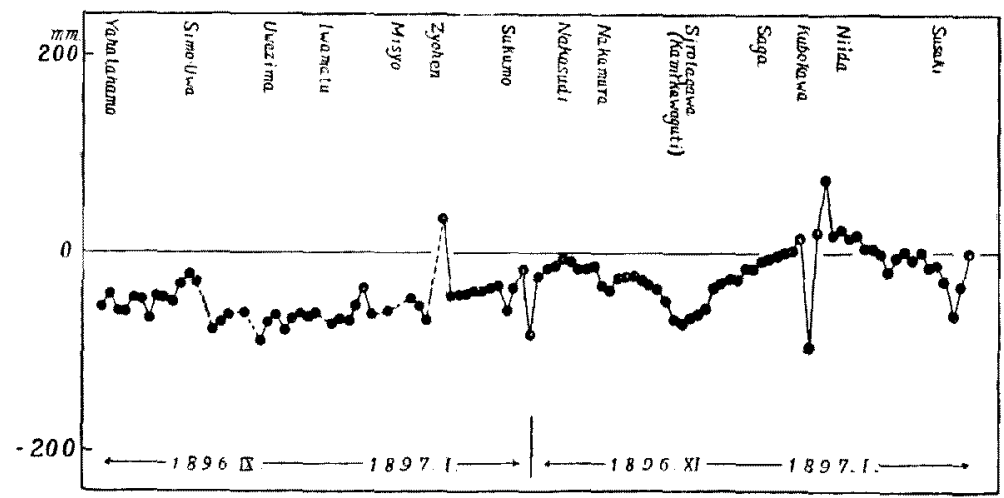

Fig. 2. Referred to B.M. No. 4677 in Gosô-mura, near Susaki, as zero.

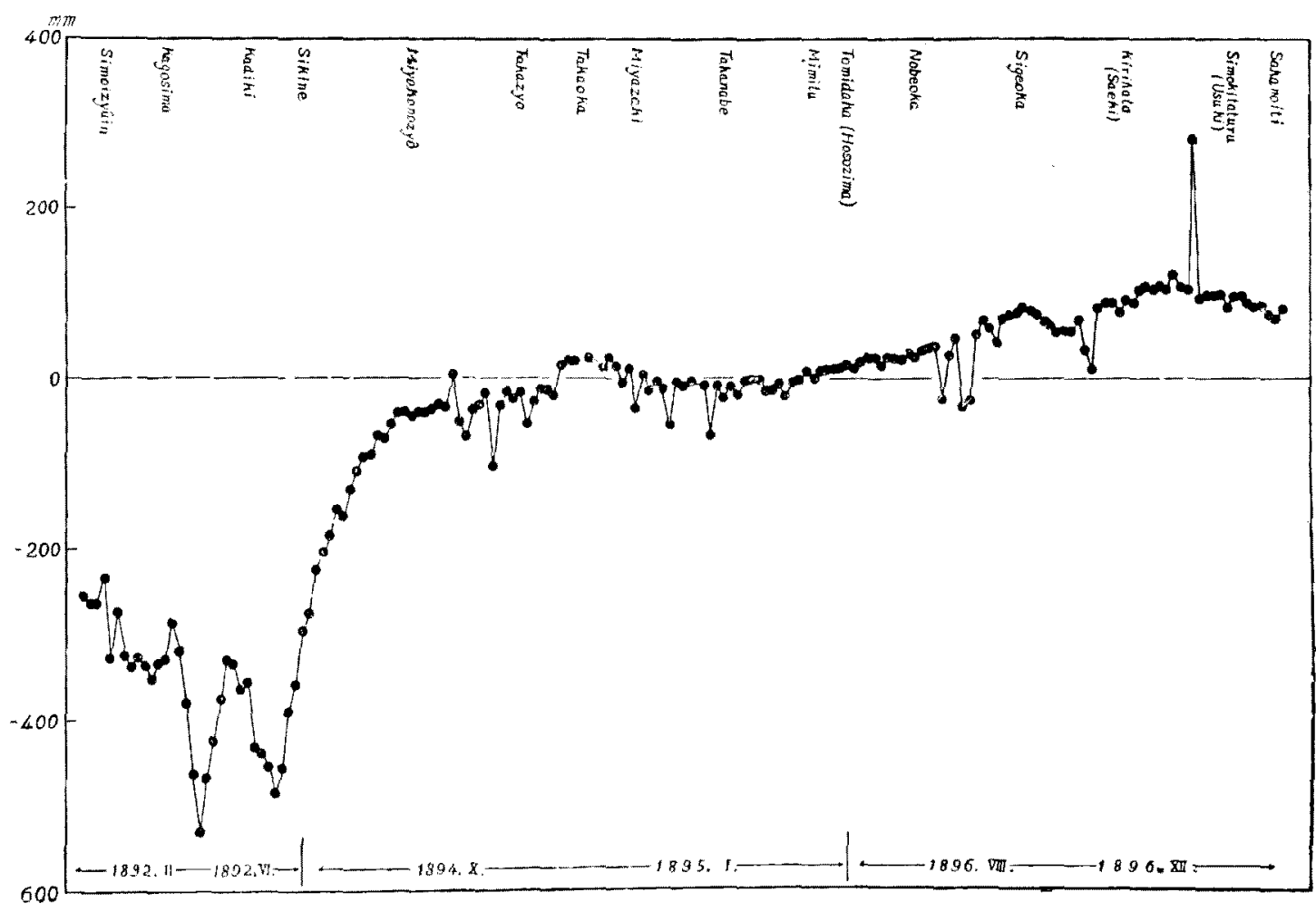

Fig. 3. Vertical displacement at the Mareogram Station of Hosozima assumed as zero. 


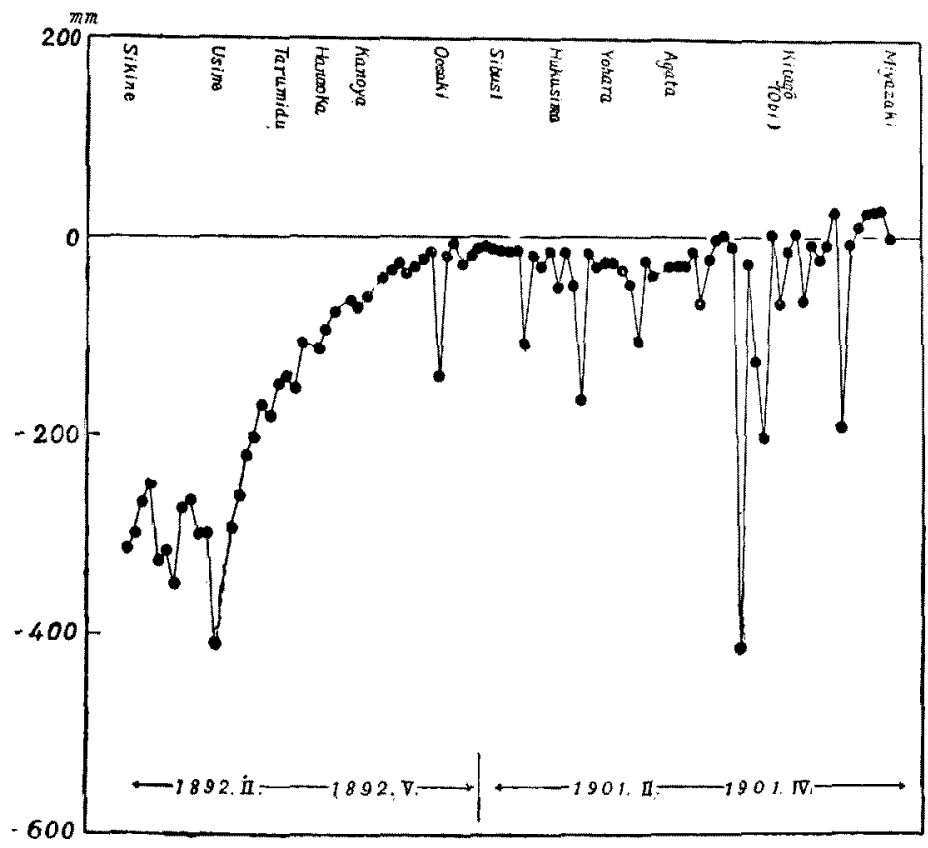

Fig. 4. Referred to Miyazaki as zero.

judged from the result of mareographic observation at Komatusima. Thence, lowering the zero line of Fig. 2 by 153.4, we may obtain the approximate amount of the displacement relative to the mean sea level at Komatusima.

It may be observed that the displacement of the western half of Sikoku is a general elevation. From Susaki to Nakamura, the trend of the displacement curve suggests a tilting or bending of the coastal crust towards the sea. ${ }^{1)}$ From Sukumo northwards, the route along the $\mathrm{W}$ coast of Sikoku shows a gradual sloping toward N. It is interesting to remark irregular fluctuations of displacements in the district characterized by the coast line of the rias-type, ${ }^{2)}$ while the other parts of the route show generally more or less smooth trend of the curve. A conspicuous discontinuity is shown near Simo-Uwa, suggesting the probable existence of an active tectonic line.

In Fig. 3, the coast of Kyûsyû, Usuki to Miyazaki, shows a general

1) In a previous paper, the author pointed out that a remarkable general tendency of southward tilting is observed of peninsulae and promontories facing the Pacific. The present route unfortunately evades the SW promontory of Tosa, so that we cannot see whether the same tendency prevails, or not, in the case of Asizurizaki. Cf. Proc. 8 (1932), 288.

2) A similar fluctuation was also observed along a coast line of the rias-type in the vicinity of Owase, $\mathrm{Kii}$, as seen in the Figure given in the author's previous paper, Proc, 8 (1932), 410, 
southward tilting, which is in opposite sense compared with the W coast of Sikoku. The northern end of this route in Kyûsyû shows, however, the same sense of tilting with the opposite coast of Sikoku. An anticlinal warping is, therefore, suggested of which the axis runs W to $\mathrm{E}$ across the Bungo Channel.

The most striking feature of Fig. 3 and 4 is the depression of land culminating in the vicinity of the volcano Sakurazima. The great depression reported by Omori immediately after the eruption of 1914 has since then gradually recovered. For example, B.M. No. 2474 at Oosaki-bana showed the displacement, referred to 1892 , of -687.3 , -623.2 and -555.1 in 1914,1915 and $1918-19$ respectively. In the last survey of 1932 the amount is still -274.0. It may be expected that the recovery will still continue for many decades of years. Whether the next eruption will occur near the end of this recovering phase, is a question left for the future.

In conclusion, the author wishes to express his acknowledgement and gratitude to the authorities of Harada-Sekizenkwai, especially to Prof. K. Ueda and Mr. M. Saitô, for the grant by means of which the present levelling survey could be carried out. ${ }^{\prime \prime}$

1) The complete data of the levelling will appear in the next number of the Bulletin of the Earthquake Research Institute. 